BULLETIN Bulletin hispanique

HISPANIQUE Université Michel de Montaigne Bordeaux

117-1 | 2015

Les poètes des rhéteurs

\title{
La batalla de los Arapiles: historia y novela
}

\section{Marisa Sotelo Vázquez}

\section{(2) OpenEdition}

Journals

Edición electrónica

URL: https://journals.openedition.org/bulletinhispanique/3842

DOI: 10.4000/bulletinhispanique.3842

ISSN: 1775-3821

\section{Editor}

Presses universitaires de Bordeaux

\section{Edición impresa}

Fecha de publicación: 1 junio 2015

Paginación: 259-278

ISBN: 979-10-300-0174-7

ISSN: 0007-4640

\section{Referencia electrónica}

Marisa Sotelo Vázquez, «La batalla de los Arapiles: historia y novela», Bulletin hispanique [En línea],

117-1 | 2015, Publicado el 01 junio 2018, consultado el 12 febrero 2022. URL: http://

journals.openedition.org/bulletinhispanique/3842 ; DOI: https://doi.org/10.4000/bulletinhispanique. 3842 


\title{
La batalla de los Arapiles: historia y novela ${ }^{1}$
}

\author{
Marisa Sotelo VÁzquez \\ Universitat de Barcelona
}

La historia suele ser más novelesca que cualquier novela. (Umberto Eco)

La batalla de los Arapiles clôture la première série des Episodios Nacionales. Cet Episodio annonce déjà les techniques narratives de la seconde série. La présente analyse s'attache à l'étude des relations entre l'histoire et le roman au travers du regard qu'une voyageuse anglaise, Miss Fly, porte sur l'Espagne et sur sa culture.

Mots-clés : Galdós, histoire, roman, feuilleton, peinture des mœurs, cervantismo.

La batalla de los Arapiles cierra la primera serie de los Episodios Nacionales y avanza en las técnicas narrativas de la siguiente. En este análisis se atiende de manera especial a las relaciones entre historia y novela, a través de la visión que de Espańa y su cultura tiene una viajera inglesa, miss Fly.

Palabras claves: Galdós, historia, novela, folletín, costumbrismo, cervantismo.

La batalla de los Arapiles ends the first sequence of los Episodios Nacionales and announces the second one's narrative technique. Our analysis focuses especially on the relations between History and Novel, through the look an English traveller, Miss Fly, casts upon the Spanish culture.

Keywords: Galdós, Historic Novel, feuilleton, Costumism (Costumbrismo), Cervantismo.

1. Este trabajo se enmarca en el Proyecto de Investigación interuniversitario, Edición y estudios críticos de la obra literaria de Benito Pérez Galdós, financiado por el Ministerio de Ciencia e Innovación (referencia: FFI2013-40766P). 
T a batalla de los Arapiles (1875) es la décima y última novela de la primera Lerie de Episodios Nacionales de Benito Pérez Galdós. Episodios que abarcan la historia de España desde la derrota de Trafalgar en 1805 a 1880, bien entrada la Restauración borbónica. Suman un total de 46 novelas, escritas entre 1873 y 1912. Esta primera serie ficcionaliza la historia y la intrahistoria española desde la mencionada batalla de Trafalgar (1805) hasta la derrota del ejército francés en los Arapiles, Salamanca (1812), episodio bélico central de la última novela, que me propongo analizar.

Todas las novelas, a excepción de Gerona, siguen las andanzas y aventuras amorosas del protagonista, Gabriel Araceli, a través de Espańa bajo el dominio del ejército francés. En todas ellas Galdós inserta personajes y lances inventados en acontecimientos históricos en un equilibrio perfecto entre historia y novela, entre vida y literatura. La batalla de los Arapiles culmina la narración de las aventuras del huérfano gaditano Gabriel Araceli durante la Guerra de Independencia entre España y Francia. En esta ocasión, Gabriel participa en aquella decisiva batalla, que marcó el fin de la dominación francesa. Asimismo, el resto de tramas secundarias de esta primera serie se resuelve en un final feliz, pues cierran la novela unas palabras de Araceli, que ha alcanzado el grado de general del ejército, en las que resuenan con fuerza las palabras finales de Lázaro de Tormes, "pues en este tiempo estaba en mi prosperidad y en la cumbre de toda buena fortuna», y aquellas otras del cierre del prólogo de la misma obra: «con fuerza y mańa, remando llegaron a buen puerto» (Lazarillo 1974: 177 y 89$)$.

\section{FeCHA DE PUbLICACIÓN Y EDICIONES}

Los diez títulos ${ }^{2}$ que abarca esta primera serie fueron escritos por el joven Galdós con extraordinaria celeridad entre 1873-1875. Concretamente, la primera edición de La batalla de los Arapiles se publica en febrero-marzo de 1875 y en 1881 aparece una edición ilustrada de las dos primeras series acompañada de una Advertencia «Al lector» en la que Galdós dice:

Tengo preparado un luengo y prolijo escrito sobre el origen de estas obras, su intención, los elementos literarios e históricos de que dispuse, los datos y anécdotas que recogí; en suma, un poquito de historia o más bien de memorias literarias, con añadidura de algunos desahogos sobre la novela contemporánea (Troncoso 2006:24)

Pero la invencible resistencia del novelista a hablar de sí mismo y su escasa afición a pontificar sobre la literatura le impidió cumplir lo prometido, desdiciéndose de ello en un segundo prólogo a dicha edición ilustrada fechado en 1885:

2. Trafalgar (1873); La Corte de Carlos IV; El 19 de marzo y el 2 de mayo; Bailén; Napoleón en Chamartin; Zaragoza; Gerona; Cádiz; Juan Martín el Empecinado y La batalla de los Arapiles (1875). 
En el breve Prólogo impreso a la cabeza de la presente edición me dejé decir que tenía preparado un largo escrito sobre el origen e intención de esta obra [...] Pronto me arrepentí de esta precipitada oferta, y la tuve por grandísima tontería en la parte que se refiere a juicios generales de crítica y opiniones sobre el género literario que más se cultiva en Espańa. Y al desempolvar los papelotes en que estaba el mal pensado y peor escrito Ensayo, me resolví airado contra mí mismo por la pícara maña de ofrecer lo que en manera alguna puedo ahora cumplir (Troncoso 2006:24).

Sin embargo, este segundo prólogo aporta más información sobre el plan completo de la obra, que, aunque algo improvisado en un principio, se fue perfilando sobre la marcha y decidió llevarlo a cabo tanto por el interés mostrado por los lectores como por la escasez en nuestra literatura de obras sobre la historia reciente. Asimismo Galdós indica cuáles fueron sus principales fuentes documentales: la prensa, la Gaceta, el Diario de Avisos y, sobre todo, la sección de anuncios, donde dice haber hallado «una mina inagotable para sacar noticias del vestir, del comer, de las pequeñas industrias, de las grandes tonterías, de los placeres y diversiones, de la supina inocencia de aquella generación» (Troncoso 2006:27). Y, por último señala también cómo se sirvió de dos libros de historia, el de Estanislao de Kostka Vayo ${ }^{3}$, y concretamente para el episodio Zaragoza los Sitios de Alcaide Ibieca. Con estas fuentes y otras, que probablemente no conocemos, Galdós consigue una perfecta ensambladura de los sucesos narrados gracias a una buena dosis de intuición, que no dejó de sorprender a uno de sus informantes contemporáneos, Mesonero Romanos, quien conservaba una memoria prodigiosa de muchos de aquellos sucesos y que en carta a Galdós sobre los Episodios le dice:

Sobre todo es sorprendente y más para mí que para ningún otro la intuición con que se apodera de épocas, escenas, y personajes (sic) que no ha conocido, y que sin embargo fotografía con una verdad pasmosa. Ya le dije a V. en otra ocasión que en tal concepto no tiene rival, y que sus novelas tienen más vida y enseñanza ejemplar que muchas historias (Ortega 1964: 24-25).

De ahí que, a pesar de que Galdós era muy reservado y escurridizo en todo, ante palabras tan entusiastas y laudatorias del Curioso parlante le agradezca públicamente su inestimable ayuda en lo referente a información de primera mano:

En las obras de este insigne fundador de la literatura de costumbres en España, en las de Larra, Miñano, Gallardo, Quintana, etc., y aun en comedias, sainetes o articulillos de escritores oscuros, así como en diferentes periódicos no políticos, sin excluir los de modas, he allegado elementos indirectos para sortear las dificultades de empresa tan ruda (Troncoso 2006:28).

Con estos mimbres de muy diversa procedencia Galdós construyó en los Episodios un verdadero fresco de la sociedad española, que ya en su tiempo gozó de una buena aceptación por parte del público. En 1934 se vuelve a editar la

3. Se refiere a la obra La historia de la vida y reinado de Fernando VII de España, Madrid, Imprenta Repullés, 1842. 
primera serie de Episodios por Hernando y posteriormente han sido editados por Aguilar (1973), Destino (2006) y la Biblioteca Castro (2007).

\section{El COMPlejo y fOlLETINESCO ASUNTO DE LA NOVELA}

El ejército aliado, formado por españoles, portugueses y británicos al mando de Lord Wellington, se encuentra en las proximidades de Salamanca, que todavía está en poder de los franceses. Una noble intelectual inglesa, miss Fly, se pasea libremente entre las tropas, respetada por sus compatriotas pero suscitando verdadero asombro entre los combatientes españoles, poco acostumbrados a una conducta tan liberal en las mujeres de la época.

Miss Fly es una romántica enferma de literatura, y enseguida cree ver en Gabriel Araceli la reencarnación de los viejos ideales medievales del honor, la virtud y el sacrificio, propios de la caballería, de modo que se encapricha de él y se empeña en seguirle en sus aventuras bélicas.

Por su parte Gabriel se entera de que su amada Inés y su padre, Santorcaz, están viviendo en Salamanca, de modo que se presenta voluntario para una suicida misión de espionaje al lugar, ya que Wellington quiere conocer con detalle las defensas que los franceses han preparado antes de proceder al asalto definitivo del territorio. Miss Fly se empeña en acompañar a Gabriel, pero éste la despista al poco de partir y llega solo a Salamanca, disfrazado de campesino para poder pasar desapercibido. Después de no pocos percances y aventuras, consigue su objetivo militar y, además, se acerca al lugar donde vive Inés, pero ella se niega a abandonar a su padre y huir con él. Unos soldados franceses lo encarcelan acusándolo de espionaje, pero miss Fly lo salva de una muerte segura al interceder por él ante el coronel Desmarets, al mando de la plaza y viejo conocido de la aristócrata inglesa.

Una vez liberado, regresan los dos a casa de Inés y Santorcaz, donde Gabriel comprende el motivo por el que su amada Inés no quiere acompañarle: en los meses que han transcurrido desde su rapto, ha aprendido a amar a su moribundo padre, en el que todos los demás no ven sino un monstruo excéntrico, perteneciente a la masonería.

Huyen de la ciudad camuflados con un grupo de masones amigos de Santorcaz, entre los que van Canencia y Monsalud. Al regresar al campamento, y pese al éxito militar de su misión, todos acusan a Gabriel de haber abusado de miss Fly y lo tratan con una frialdad cercana a la violencia, incluso lord Wellington y la misma condesa Amaranta, que ha venido desde Madrid para reencontrarse con su hija Inés.

Poco después comienza la batalla de los Arapiles con Gabriel en la vanguardia del ejército aliado. Su comportamiento heroico y temerario hace que sea herido gravemente en el combate. Durante su convalecencia, miss Fly le confiesa su amor e insinúa que ha dejado que corra el rumor del supuesto abuso para obligarle a contraer matrimonio con ella. Pero Gabriel, cual nuevo don Quijote, sólo tiene en su pensamiento a Inés. Comprendiendo su derrota, 
miss Fly aclara la situación, e Inés y Amaranta llevan a Gabriel a Salamanca, a casa de Santorcaz.

Al final, Santorcaz, a punto de morir y redimido por el amor de su hija, se arrepiente de sus fechorías y hace las paces con Amaranta. Se perdonan mutuamente. Gabriel también le perdona, y ve en don Luis al hombre en que él si hubiera convertido si le hubieran arrebatado a Inés.

\section{TEMAS, INFLUENCIAS Y MODELOS}

La batalla de los Arapiles es una novela de una extensión superior a las demás que forman la primera serie. Con una trama novelesca muy elástica en la que cabe todo: historia, aventuras, folletín, romanticismo, costumbrismo, cervantismo e influencias de la picaresca. Predominan los elementos novelescos aunque los sucesos históricos sean esencialísimos para fijar la densa trama argumental. Entre los temas presentes en este episodio sobresalen:

a) El dominio de las tácticas militares, sobre las que sin duda Galdós tuvo que documentarse en libros de historia o de estrategia militar y bélica.

b) La conflictiva presencia de los afrancesados en la sociedad española con los que Galdós es bastante respetuoso, aunque se muestra mucho más intolerante con los masones, personificados en la figura de Santorcaz y su cuadrilla, de la que formará parte también Monsalud, protagonista de la segunda serie.

c) El costumbrismo a través no sólo de la influencia de la literatura costumbrista sino de los recuerdos personales de Mesonero que fueron muy útiles para el primer Galdós. En consecuencia, las fuentes del costumbrismo galdosiano fueron librescas pero también orales. En este sentido vuelve a ser muy elocuente otra carta de Mesonero:

lo digo con franqueza la poderosa inventiva de V., su sagacidad y la destreza para continuar en los términos más brillantes el desarrollo de su drama y combinarlo acertadísimamente con la marcha de los sucesos históricos. Es una especialidad en que no tiene V. rival, y me admira tanto más, quanto (sic) que habiendo sido testigo (acaso ya único) de esos sucesos, y hablado con V. largamente sobre ellos, estoy en el caso de apreciar la inmensa fuerza de intuición con que $\mathrm{V}$. son su clarísimo ingenio se hace dueño de situaciones, caracteres y períodos históricos que sólo ha podido escuchar de mi boca, o leer en tal o qual (sic) libro o periódico (Ortega 1964:24-25)

d) La visión del romanticismo español, como algo exótico, con abundantes reminiscencias medievales y caballerescas, que es la visión que tiene miss Fly, muy similar a la que podemos encontrar en el relato de viajes de George Borrow La Biblia en España (1842). Por ello pudo escribir Manuel Azaña en su nota preliminar a la traducción española: 
El lector apreciará seguramente en La Biblia en España, a pesar de la traducción descolorida, el novelesco interés de algunos pasajes que parecen arrancados de libro picaresco, el movimiento de ciertos cuadros, propio de un «episodio nacional», el sabor de otras escenas de costumbres, los bosquejos de tipos y caracteres, con tantos otros méritos que es innecesario señalar (Azaña 1967: 23).

e) También son notables las descripciones de paisajes y ciudades, que adelantan las dotes de observación ambiental que caracterizarán al gran novelista y autor de libros de viaje.

En cuanto a las influencias y modelos, es decisiva la influencia de la novela histórica europea, singularmente de las obras de Walter Scott. Además, aunque no es probable que Galdós conociera por estas fechas el Avant-propos a la Comedia Humana, en el que Balzac ${ }^{4}$ explica el valor de las novelas históricas de Walter Scott y a la vez señala lo que a su juicio era el fallo primordial, la falta de conexión entre unas y otras, coincide con el novelista francés en el objetivo de escribir la novela panorámica de toda una época. En este sentido los Episodios galdosianos están más cerca del proyecto de Balzac que de las novelas del escocés:

Así, pues, Walter Scott elevaba a valor filosófico de la historia la novela, esa literatura que, de siglo en siglo, incrusta de inmortales diamantes la corona poética de aquellos países en que se cultivan las Letras. Infundíale el espíritu de los antiguos tiempos, reunía en ella el drama, el diálogo, el retrato, el paisaje, la descripción; daba entrada en ella a lo maravilloso y lo verdadero, esos elementos de la epopeya, y hacía que con la poesía se codease la familiaridad de los lenguajes más humildes. Pero, como más bien que imaginar un sistema lo que hizo fue encontrar su manera propia en el fuego del trabajo o en virtud de la lógica de ese trabajo mismo, no pensó en ligar unas a otras sus composiciones de modo que se coordinasen en una historia completa de la que cada capítulo hubiera sido una novela y cada novela una época. Al notar yo esa falta de enlace, que, por otro lado, no resta grandeza al escocés, vislumbré al mismo tiempo el sistema favorable a la ejecución de mi obra y la posibilidad de realizarla.

$[\ldots]$

La sociedad francesa sería el historiador y yo no tendría que ser sino su secretario. Al hacer el inventario de vicios y virtudes, al reunir los principales hechos de las presiones, pintar los caracteres, elegir los principales acaecimientos de la sociedad, componer tipos mediante la fusión de rasgos de varios caracteres homogéneos, quizá podría yo llegar a escribir esa historia olvidada por los historiadores, la de las costumbres. (Balzac 1842: 6)

Cabe señalar, a continuación, la huella de las novelas folletinescas, que se percibe en el tratamiento de los sucesos y, sobre todo, en la estructura de la novela con la multitud de lances que componen la compleja trama argumental. En 1866 escribe Galdós a propósito de la poética narrativa y veladamente ironiza sobre los ingredientes del folletín, que demuestra conocer muy bien:

4. Galdós dice en Memorias de un desmemoriado, que descubrió a Balzac en su viaje a París a finales de la década de los setenta, precisamente paseando por los quais del Sena, donde compró Eugénie Grandet. 
¡La novela! Dennos novelas históricas y sociales, novelas intencionadas, profundas; novelas de color subido, rojas, verdinegras, jaspeadas. Píntennos las pasiones con rasgos brillantes, detalles gráficos que nos hagan saltar del asiento. Queremos ver descrita con mano segura las peripecias más atroces que imaginación alguna pueda concebir; hágasenos relación especialmente de los crímenes más abominables...; queremos ver al suicida, a la adúltera, a la mujer pública, al baratero, al gitano; si hay hospital, mejor; si hay tisis regeneradora, ¡magnífico!; si hay patíbulo, ¡soberbio!... Realidad, realidad; escríbannos la verdad de las miserias sociales esos escritores señalados por el dedo de la gacetilla, santificados por el repartidor, canonizados por el prospecto.Dennos impresiones fuertes, un cangilón de acíbar y otro de menta en cada página, aunque la pintura de caracteres no sea muy feliz y el sostenimiento de los mismos esté un poco descuidado; dennos un puńal que destile sangre y ocho corazones que destilen hiel, aunque el plan no peque de verosímil y el ideal poético brille por su ausencia. Realidad, realidad; queremos ver el mundo tal cual es, la sociedad tal cual es, inmunda, corrompida, escéptica, cenagosa, fangosa, etc. Poco importa que las concordancias gramaticales sean un tanto vizcaínas y los giros un poquito transpirenaicos. ¡Realidad, realidad! (Montesinos 1980: 26).

Y, por último, debemos apuntar también el sustrato de la mejor tradición española, tan a menudo presente a través de la novela picaresca y las novelas de caballerías, muy especialmente de El Quijote. La batalla de los Arapiles es probablemente la novela de la primera serie más impregnada de elementos cervantinos, tal como apunta Rubén Benítez cuando escribe que «es casi producto de un reflejo condicionado, sin control de la voluntad, que origina mecánicamente Quijotes y Sanchos; cada acción se torna lucha con molinos de viento, cada cambio obra de nigromantes y encantadores, cada amor la transformación ideal de rústicas en Dulcineas, cada cueva antro de imaginadas figuraciones» (Benítez 1990:51).

El cervantismo aparece estrechamente ligado a las aventuras del protagonista Gabriel Araceli, pero también a las de otros personajes como Inés, a menudo comparada con Dulcinea; en los extravagantes Santorcaz, Juan de Dios, Tribaldos, Canencia o el lunático España, herederos de pura cepa de la locura quijotesca. También la visión de la realidad de miss Fly se contagia de quijotismo. Y, por último, la influencia de Cervantes está presente en elementos estructurales, como los engarces de final y comienzo de capítulo, la interpolación de aventuras; o la resolución de algunas de ellas por métodos que tienen que ver con la creencia en encantamientos propios de la literatura caballeresca. Porque como dejó escrito Montesinos: «Cervantes le ha hecho a Galdós los ojos» (Montesinos 1980: XVII) y esta novela lo prueba.

\section{PoÉtica narrativa}

La batalla de los Arapiles empieza con una fórmula epistolar, adopta después la forma autobiográfica en los capítulos centrales y termina con un epílogo a la primera edición de la novela, fechado en 1875, en el que Galdós justifica el final con un texto titulado "Hasta luego", que contiene una serie de interesantes reflexiones estéticas. El texto, que no se ha reproducido en ediciones posteriores, 
fue rescatado por Alan E. Smith (1982:105-108). En él «Galdós se describe a sí mismo como un novelista impetuoso y descuidado", sin embargo, esta afirmación se desmiente por sí sola en las líneas siguientes, en las que queda patente no solo una temprana conciencia artística sino que además se esbozan algunos elementos muy reveladores de una verdadera poética de la novela histórica, que vamos a sintetizar a continuación.

En primer lugar, Galdós lamenta la falta de datos y documentos históricos en algunos momentos de la composición de la primera serie:

[...] he hallado a mi paso, quizás a causa del asunto mismo, contrariedades inmensas, cuales son la falta de datos que para componer esta clase de obras se necesitan y la carencia de documentos privados, memorias o historias individuales y anecdóticas, sin cuyos preciosos materiales, el trabajo inductivo del novelista de este género es fatigoso y casi siempre estéril (Smith 1982: 106).

A continuación, se acusa a sí mismo de cierta impaciencia, «que no puedo de modo alguno refrenar, me han impulsado a escribir las cinco mil quinientas páginas de estos Episodios Nacionales, con bastante precipitación» (Smith 1982:106). Precipitación que le ha llevado a cometer errores como los derivados de la adopción de la fórmula autobiográfica y las dificultades de hacerla compatible en las novelas de la primera serie con la necesaria verosimilitud. Por ello decide renunciar al autobiografismo, ya que en las novelas históricas hay multitud de sucesos reales que la fantasía personal no puede alterar, sino que debe tratar de reproducir con objetividad:

La forma autobiográfica [...] si bien no carece de encanto, tiene grandísimos inconvenientes para una narración larga y no puede de modo alguno sostenerse en el género novelesco-histórico, donde la acción y la trama se construyen con multitud de sucesos que no debe alterar la fantasía, y con personajes de existencia real. Únanse a esto las escenas y tipos que el novelista tiene que sacar de sus propios talleres; establézcase la necesidad de que los acontecimientos históricos ocurridos en palacios, en campos de batalla, en asambleas, en los clubs, en mil sitios diversos y de no libre elección para el autor, han de pasar ante los ojos de un solo personaje, narrador obligado e indispensable de tan diversos hechos en período de tiempo larguísimo y en diferentes ocasiones y lugares, y se comprenderá que la fórmula autobiográfica es un obstáculo constante a la libertad del novelista y a la puntualidad del historiador. (Smith 1982: 106)

Y añade, matizando aún más el valor de la autobiografía: «Quizás tenga ella la culpa de que no lograra yo siempre una perfecta combinación entre la historia y la novela» (Smith 1982: 106). Reflexión que reaparece en la última novela de la segunda serie Un faccioso más y algunos frailes menos cuando vuelve a insistir: «En la primera serie adopté la forma autobiográfica, que tiene por sí mucho atractivo y favorece la unidad; pero impone cierta rigidez de procedimiento y pone mil trabas a las narraciones largas» (cap. XXXI, p. II).

En tercer lugar, a pesar de todas estas dificultades y defectos de forma que dice conocer y se propone enmendar, Galdós promete continuar la empresa y escribir una segunda serie: «Escribiré, pues, una segunda serie, para aprovechar 
la riquísima materia que en la historia y en las costumbres ofrece el interesante período contenido entre las dos grandes guerras españolas del presente siglo» (Smith 1982: 107).

Cierra, seguidamente, la interesante reflexión sobre la poética narrativa comunicando al lector sus intenciones futuras de construir un gran fresco histórico-social, capaz de ofrecer noticia de todas las grandes transformaciones públicas y privadas del siglo, así como promete poner en acción a la mayoría de personajes que quedaron con vida en la primera serie:

Renunciando a la narración primo-personal como forma sistemática, publicaré otros diez volúmenes, enlazados entre sí [...] unidos también a la primera serie, cuyo pensamiento desarrollarán en la parte histórica y en la imaginaria, pretendiendo ofrecer un cuadro lo más completo posible de la transformación de la sociedad española en el presente siglo, de sus pasiones buenas y malas, de su especial sentir y pensar en la vida pública y en la privada (Smith 1982: 107).

Tras estas palabras late de nuevo un propósito muy similar al que guía $\mathrm{La}$ comedia humana de Balzac.

Y, por último, señala que, para construir ese magnífico fresco histórico-social, necesita de múltiples personajes, que - dice- bullen en su interior y a los que se ve obligado a refrenar pues han de ser objeto de revisión, remiendo, nueva pintura, como si se tratara de poner en pie un verdadero retablo dramático:

Sordo todavía a sus ruegos, y deseoso de que salgan con todos los atavíos y toda la decencia y pulcritud y fino comedimiento que mis amables favorecedores exigen, les cojo, les limpio el polvo de dos años, les remiendo o renuevo sus ya viejas casacas y guardapiés, les aliño las pálidas caras, les doy nueva y más fuerte mano de pintura, les compongo los alambres rotos, los resortes enmohecidos, las piezas gastadas, y dando general barrido al viejo tabladillo, y frotes y abluciones a todos los trebejos, lienzos y cachivaches, ofrezco al público la Segunda serie de los Episodios Nacionales (Smith 1982: 107$)^{5}$.

\section{Historia Y NOVELA}

Para la escritura de los Episodios Nacionales Galdós se basó, como hemos visto, en hechos históricos que conocía a través de la lectura o a través de la transmisión oral. Concretamente para este Episodio con toda seguridad el autor se documentó en la Historia de Toreno, aunque no haya una exacta correspondencia entre los datos históricos y los novelados.

5. Integrada por los tomos siguientes, escritos entre 1875 y 1879: El equipaje del Rey José. Memorias de un cortesano de 1815. La segunda casaca. El Grande Oriente. 7 de Julio. Los cien mil hijos de San Luis. El Terror de 1824. Un voluntario realista. Los apostólicos. Un faccioso más $y$ algunos frailes menos. No es la primera vez ni será la última que Galdós utilice expresiones o recursos dramáticos en su poética narrativa y, más concretamente, en los Episodios, Cf. Ermitas Penas "La estética teatral de la segunda serie de los Episodios nacionales galdosianos», Estéticas y estilos en la literatura española del siglo XIX, Actas del V Coloquio de la Sociedad de Literatura Española del Siglo XIX. Ermitas Penas 2014: 327-347. 
Los hechos históricos comprobados de este episodio son realmente pocos, sin embargo los lances novelescos de raigambre folletinesca, como se deduce del resumen argumental, son muy abundantes. Galdós, buen lector de folletines y, sobre todo, gran admirador y lector de Cervantes, juega continuamente a intercalar sucesos novelescos en torno al episodio histórico de la última batalla del ejército aliado contra el francés.

La influencia de Cervantes es muy evidente a lo largo de toda la novela, pues Galdós no se conforma con la mera imitación de frases, giros o elementos estructurales, sino que parece entablar un verdadero diálogo con el autor del Quijote de creador a creador, de novelista a novelista, para defender en estos momentos una postura radicalmente antiquijotesca. La solución a los problemas de Espańa vendrá de la mano de la cordura y la sensatez, nunca de la locura, aunque esta sea de raíz idealista.

La fórmula narrativa elegida es, como en el resto de los Episodios Nacionales de esta primera serie, la forma autobiográfica. La primera persona narrativa hace que Gabriel Araceli sea el narrador y a la vez el protagonista de los principales episodios narrados. De ahí que Galdós opte por un narrador anciano que se remonta a los años de su nińez para evocar su larga y azarosa vida hasta alcanzar el grado de general. El relato autobiográfico cohesiona la narración en torno a la figura del narrador-protagonista, Gabriel Araceli, y a la vez refuerza la credibilidad de lo narrado.

En otro orden de cosas, tal como la crítica ha señalado, la elección de un yo-narrador resulta sumamente útil, pues nos permite observar la ideología del joven Galdós cuando inicia su carrera novelística:

Lleno de confianza en la capacidad emprendedora de la clase media ${ }^{6}$ y en sus posibilidades de transformar la sociedad, propone como protagonista modelo a un personaje de origen popular que, gracias a su trabajo y honradez, llegará a ser respetado como oficial del ejército y emparentará en matrimonio con la aristocracia (Troncoso 2006:11).

El mensaje de la novela y por ende de la primera serie de Episodios Nacionales con evidentes huellas de Lazarillo de Tormes - «la vida fue mi escuela, y la desgracia mi maestra» (Galdós 2007: 485)- es manifiestamente antiquijotesco, pues solo el cuerdo, nunca el loco, puede ser dueño de sus destinos; la vida ha de ser esfuerzo e ideal, tal como evidencia la lectura del epílogo de Araceli:

Adiós mis queridos amigos. No me atrevo a deciros que me imitéis, pues sería inmodestia; pero si sois jóvenes, si os halláis postergados por la fortuna, si encontráis ante vuestros ojos montañas escarpadas, inaccesibles alturas, y no tenéis escalas ni cuerdas, pero sí manos vigorosas; si os halláis imposibilitados para realizar en el mundo los generosos impulsos del pensamiento y las leyes del corazón, acordaos de Gabriel Araceli, que nació sin nada y lo tuvo todo (Galdós 2007: 486).

6. «Pero la clase media, la más olvidada por nuestros novelistas, es el gran modelo, la fuente inagotable. Ella es hoy la base del orden social: ella asume por su iniciativa y por su inteligencia la soberanía de las naciones, y en ella está el hombre del siglo XIX con sus virtudes y sus vicios, su noble e insaciable aspiración, su afán de reformas, su actividad pasmosa» (Galdós, «Observaciones sobre la novela española contemporánea», p. 112). 


\section{Miss Fly y SU VISIÓN DE EsPaña}

Esta última novela de la primera serie presenta un gran número de personajes con una participación más o menos importante en la trama argumental: Gabriel Araceli, el protagonista, Inés, la condesa Amaranta, Miss Fly, Santorcaz, Juan de Dios, Bartolomé Canencia, Carlos España, son los personajes fundamentales de este episodio. Además del protagonista, algunos ya habían aparecido en novelas anteriores dando pie a los que sostienen, como Montesinos (1978:75119), que las diez novelas, aunque independientes, pueden funcionar como una única novela, en la que esta décima entrega sería el capítulo final, como un gran fresco histórico que puede emular a otros modelos europeos tales como La comedia humana de Balzac o Guerra y paz de Tolstoi.

Miss Fly, como antes Lord Gray (caricatura de Lord Byron) en Cádiz, es portavoz de las ideas de Galdós a propósito del temperamento inglés, a la vez que le sirven de contrapunto para analizar el carácter español desde la mirada europea. Ambos acuden a España en busca de aventuras guerreras, de pasión amorosa y, sobre todo, atraídos por la poesía y el exotismo de nuestras costumbres. Tienen una visión romántica de España, en la que prima la atracción por la literatura medieval y por los libros de caballerías. También en este episodio aparecen otros personajes que se convertirán en fundamentales en la segunda serie, tal es el caso de Salvador Monsalud, integrante de la cofradía masónica de Santorcaz, verdadero protagonista de aquella. Los personajes históricos reales como Moratín, el Abate Marchena, José Bonaparte y el general Wellington tienen una presencia circunstancial en la novela, aunque son los que contribuyen de manera decisiva a dotar de verosimilitud al argumento.

Las valoraciones críticas sobre los personajes secundarios de esta novela son prácticamente inexistentes, si exceptuamos un breve comentario de Montesinos (1980:85) en el que señala la importancia excesiva que Galdós concede a un personaje aparentemente secundario como Miss Fly. Evidentemente la voz narrativa principal sigue siendo la de Gabriel Araceli, que es el que da cohesión a las diez novelas que integran la primera serie, pero indudablemente la inglesa, que es como se refieren a ella los demás personajes, cobra un protagonismo muy destacado, tanto que, como es también frecuente en Galdós, sus andanzas podrían haberse convertido en una novela independiente. En uno de los capítulos finales Gabriel Araceli, narrador-protagonista y portavoz del propio autor, como si fuese consciente de ello escribe: «Nos hallábamos solos [Inés y Gabriel] y le conté toda, absolutamente toda la casi increíble novela de miss Fly, sin omitir nada que me perjudicase o me engrandeciese a los ojos de mi interlocutora» (Galdós 2007: 466). Es decir, que Galdós es consciente de que está contando una novela dentro de la novela, como ocurre tan a menudo en El Quijote, en el que los personajes se convierten en narradores de historias secundarias hábilmente interpoladas en la trama argumental.

¿Quién es esta mujer? y ¿qué función desempeña en la novela? La primera aparición en la historia de esta exótica y algo extravagante viajera inglesa se 
produce en el capítulo VII, en el que Galdós nos proporciona un espléndido retrato físico y moral de Athenais, miss Fly. Retrato que subraya el contraste entre las costumbres de esta mujer soltera, joven y bella, que viaja sola y se mueve con entera libertad entre las filas del ejército inglés frente a vida y costumbres de las mujeres españolas:

Sir Tomás Parr habló largamente en inglés con la bella desconocida y después se despidió. No dejaba de causarme sorpresa que sus compatriotas abandonasen a aquella hermosa mujer que sin duda debía tener esposo o hermanos en el ejército; pero dije para mí: «Será que las costumbres inglesas lo ordenan de este modo» (Galdós 2007: 252-3)

El retrato físico, aparte de la fidelidad al tipo racial característico de mujer inglesa, está construido a partir de una serie de rasgos del canon de belleza femenino vigente desde el Renacimiento, que el propio Galdós se encarga de subrayar con un buen número de guiños a la tradición clásica:

No puedo dar idea de la extremada belleza de sus ojos azules. Todas las facciones de su rostro distinguíanse por la más pura corrección y finura. Los cabellos rubios hacían verosímil la imagen de las trenzas de oro tan usada por los poetas, y acompañaban la boca los más lindos y blancos dientes que pueden verse. Su cuerpo atormentado bajo las ballenas de un apretado jubón, del cual pendían faldas de amazona, era delgadísimo, mas no carecía de las redondeces y elegantes contornos y desigualdades que distinguen a una mujer de un palo torneado (Galdós 2007: 253)

La ironía galdosiana presente en el apellido Fly (mosca y vuelo) ${ }^{7}$ se plasma en el contrapunto entre la imagen estilizada de la inglesa, su manera de vestir como una amazona y su excentricidad de pedir una taza de té en una castiza venta castellana, regentada por la señora de Forgolleda, que tiene una pésima impresión de los ingleses, a los que considera «herejes, luteranos y calvinistas» (Galdós 2007: 254). Por contrapartida a la actitud doméstica y timorata de las figuras femeninas españolas de la novela, incluso de Inés, miss Fly expone con total naturalidad cuáles fueron los motivos que la impulsaron a viajar a Espańa, sobre todo para establecer diferencia con "las mujeres de mala vida», que acompañaban al ejército francés. La inglesa explica que vino a España con su hermano, que había muerto combatiendo en la batalla de la Albuera, y a partir de entonces se impuso el deber de recuperar su cuerpo para enviarlo a Inglaterra, al panteón familiar, pero al mismo tiempo decidió quedarse, seducida por las costumbres y caracteres de nuestro país:

En poco tiempo cumplí esta triste misión, y hallándome sola traté de volver a mi país. Pero al mismo tiempo me cautivaban de tal modo la historia, las tradiciones, las costumbres, la literatura, las artes, las ruinas, la música popular, los bailes, los trajes de esta nación tan grande en otro tiempo y otra vez grandísima en la época presente, que formé proyecto de quedarme aquí para estudiarlo todo (Galdós 2007: 255).

7. Es evidente el sesgo irónico del apellido de miss Fly. Galdós juega con el doble significado del término, mosca para simbolizar cómo miss Fly no se separa de Gabriel Araceli, y también con el significado derivado del verbo volar, para simbolizar el vuelo desbordante de su imaginación, de su fantasía, que es una de las características fundamentales de su carácter. 
Es evidente que miss Fly tiene una visión idealizada y romántica de España y que su curiosidad es propia de «artista y de viajera» aficionada a visitar «abadías, castillos y catedrales» (Galdós 2007:259). A esta curiosidad característica de muchos viajeros románticos que visitaron España en busca de belleza, aventuras y exotismo hay que añadir en el caso de miss Fly «una imaginación exaltada y novelesca», que se contagia de la literatura a la que es tan aficionada y en este sentido es también un personaje de raigambre cervantina. Los libros de caballería, los romances son las fuentes de que se nutre su exaltada fantasía, que la lleva a imaginar que los españoles con los que trata en pleno siglo XIX son valerosos descendientes de aquellos caballeros que fueron «asombro y envidia de Europa por espacio de muchos siglos» (Galdós 2007: 259). Intoxicada de literatura caballeresca y de romances heroicos que «suspenden el ánimo, despiertan la sensibilidad, avivan el valor, infunden entusiasmo por las grandes acciones, engrandecen la gloria y achican el peligro en todos los momentos de la vida» (Galdós 2007: 261), espera vivir en la realidad cotidiana los lances que han alimentado su fantasía mediante la lectura.

El contraste entre la vida de esta mujer, que defiende su independencia amparándose en las leyes de su país, y la vida en España es motivo de esta elocuente y curiosa conversación entre ella y Araceli, que permite no solo conocer lo que piensa la inglesa sino también la imagen que los espańoles tienen de sí mismos y de su patria:

-Sabe Dios qué casta de pájaro serás tú -dije para mi capote; y luego en voz alta añadí, sosteniendo fijamente la dulce mirada de sus ojos de cielo-: «iY los padres de usted consintieron, sin reparar en los continuos y graves peligros a que está expuesta una tierna doncella sola y sin amparo en país extranjero, en medio de un ejército! Señora, por amor de Dios...»

-¡Ah!, no conocéis sin duda que nosotras, las hijas de Inglaterra, estamos protegidas por las leyes de tal manera y con tal rigor, que ningún hombre se atreve a faltarnos al respeto

$[\ldots .$.

- ¡Pero estamos en España, señora, en España! Usted no sabe en qué país se ha metido.

-Pero sigo al ejército aliado y estoy al amparo de las leyes inglesas -dijo sonriendo-. Caballero, faltad al pudor si os parece, intentad galantearme de una manera menos decorosa que la que empleáis para amar a esa Dulcinea que fue causa de la muerte de Gray, y Lord Wellington os mandará fusilar si no os casáis conmigo (Galdós 2007: 255-256).

La vida para esta inglesa «andariega y voluntariosa» es «libertad, independencia, iniciativa, arrojo", por ello no duda en seguir a Araceli en todas sus andanzas porque de él le atrae tanto la aventura militar como la sentimental de intentar rescatar a su amada Inés, secuestrada por su padre, el masón Santorcaz, en un vetusto caserón de la calle del Cáliz de Salamanca. Por tanto, cuando miss Fly conoce el objetivo de Araceli de liberar a Inés se entusiasma hasta defender que la realidad en España es mucho más poética que la literatura:

- ¡Caballero! -exclamó, sin ocultar el expansivo y grandioso arrobamiento de su alma poética-, esto es hermosísimo, tan hermoso que no parece real. Lo que yo 
sospechaba y acaba de revelárseme por completo tiene tanta belleza como las mentiras de los romances y las novelas. De modo que vos al ir a Salamanca vais a intentar... (Galdós 2007: 280).

E insiste en que sucesos de este tipo sólo podían darse en España. La conversación con Araceli es uno de los pasajes más reveladores de la novela, pues permite aquilatar un rasgo claramente cervantino, la importancia de la literatura proyectándose sobre la vida y la realidad hasta transformarla. Rasgo del que no escapa ni siquiera el personaje que nos contempla desde fuera de nuestra tradición cultural:

-[...] En Espańa, sólo en España podría encontrarse esto que enciende el corazón, despierta la fantasía y da a la vida el aliciente de vivas pasiones que necesita. Una joven robada, un caballero leal que, despreciando toda clase de peligros, va en su busca y penetra con ánimo fuerte en una plaza enemiga, y aspira sólo con el valor de su corazón y los ardides de su ingenio a arrancar el objeto amado de las bárbaras manos que lo aprisionan...¡ Oh, qué aventura tan hermosa! ¡Qué romance tan lindo!

-¿Gustan a usted, señora, las aventuras y los romances?

-¿Que si me gustan? ¡Me encantan, me enamoran, me cautivan más que ninguna lectura de cuantas han inventado los ingenios de la tierra! -repuso con entusiasmo-. ¡Los romances! ¿Hay nada más hermoso, ni que con elocuencia más dulce y majestuosa hable a nuestra alma? Los he leído y los conozco todos, los moriscos, los históricos, los caballerescos, los amorosos, los devotos, los vulgares, los de cautivos y forzados, y los satíricos. Los leo con pasión, he traducido muchos al inglés en verso o prosa.

- ¡Oh, señora mía e insigne maestra! -dije, afirmando para mí que la enfermedad moral de miss Fly era una monomanía literaria-. ¡Cuánto deben a usted las letras españolas! (Galdós 2007: 281).

Como se deduce de estas palabras, la inglesa, como don Quijote, confiesa leer con pasión y buscar después infructuosamente en la vida real el equivalente de los lances literarios. Proyectar la literatura sobre la vida es lo que llevó al hidalgo manchego a correr toda clase de aventuras en busca de los ideales caballerescos ya periclitados. Y de la misma manera que las aventuras de don Quijote resultaban en su tiempo anacrónicas, las aventuras romancescas y caballerescas que miss Fly desea encontrar en la realidad espańola del siglo XIX ya no existen. Por ello, Araceli, cual renovado Sansón Carrasco, sentencia con rotundidad: «esos tiempos pasaron, ya no hay Lindarajas, ni Tarfes, ni Bravoneles, ni Melisendras» (Galdós 2007: 281).

La influencia de Cervantes sobre este personaje de corte claramente romántico va más allá de su concepción de la realidad e inunda también el estilo, porque, como ha señalado Montesinos «cuando miss Fly elogia los libros de caballería el compás del período es cervantino puro» (Montesinos 1980:105).

No obstante, la ironía de Galdós es evidente en los pasajes más radicalmente cervantinos, pues hace que la realidad más prosaica se imponga a la pasión aventurera de miss Fly. De manera que la vejez y cojera de su caballo, que casi no se tiene en pie, hace que no pueda seguir a Araceli en su camino hacia Salamanca. No parece sino que Galdós refrena los impulsos quiméricos de su personaje enfrentándola a la prosaica realidad desposeída de poesía y belleza: 
-Parece que resucitan los tiempos -dijo miss Fly con cierta vaguedad inexplicable [...] La Naturaleza, aburrida de la vulgaridad presente, se viste con las galas de su juventud, como una vieja que no quiere serlo... Retrocede la Historia, cansada de hacer tonterías, y con pueril entusiasmo hojea las páginas de su propio diario y luego busca la espada en el cajón de los olvidados y sublimes juguetes... ¿Pero no veis esto, Araceli, no lo veis?

-Señora, ¿qué quiere usted que vea?

-El romance de Bernardo y de la hermosa Estela, que por segunda vez....

Al decir esto, el caballo que arrastraba no sin trabajo el carricoche de la poética Athenais empezó a cojear, sin duda porque no podía reverdecer, como la Historia, las lozanas robusteces y agilidades de su juventud (Galdós 2007: 282).

En otro momento será el propio Araceli -que dice desconocer el sentimentalismo tan de moda en los países del norte-, quien le recordará que vida y literatura son cosas muy distintas. Y que en todo caso, siempre es más rica, más compleja, menos predecible y más azarosa la vida que las aventuras narradas en las novelas o en los romances:

-Usted cree que todos los lances de amor y de aventura han de pasar en el mundo conforme a lo que ha leído en las novelas, en los romances, en las obras de los grandes poetas y escritores, y no advierte que las cosas extrańas y dramáticas suelen verse antes en la vida que en los libros, llenos de ficciones convencionales y que se reproducen unas a otras. Los poetas copian de sus predecesores, los cuales copiaron de otros más antiguos, y mientras fabrican este mundo vano no advierten que la naturaleza y la sociedad van creando a escondidas del público y recatándose de la imprenta mil novedades que espantan o enamoran.

Yo hacía esfuerzos de ingenio por sostener de algún modo un coloquio en que miss Fly con su ardoroso sentimiento poético me llevaba ventaja, y a cada palabra mía su atrevida imaginación se inflamaba más volando en pos de sucesos raros, desconocidos, novelescos, fuente de pasión y de idealismo. No puedo negar que Athenais me causaba sorpresa, porque yo, en mi ignorancia, no conocía el sentimentalismo que entonces estaba en moda entre la gente del Norte, invadiendo literatura y sociedad de un modo extraordinario (Galdós 2007: 334-335).

Por último, es preciso también resaltar que en el arrobamiento contemplativo de miss Fly ante los monumentos de Salamanca, llamada Roma la chica, en que resuenan de nuevo ecos cervantinos del magnífico discurso de don Quijote sobre «La Edad de Oro», está en germen la mirada sagaz del Galdós magnífico autor de crónicas de viaje:

-¿Qué hermosa ciudad! -dijo miss Fly con arrobamiento contemplativo-. Todo aquí respira la grandeza de una edad gloriosa e ilustre. ¡Cuán excelsos, cuán poderosos no han sido los sentimientos que han necesitado tanta, tantísima piedra para manifestarse! ¿Para vos no dicen nada esas altas torres, esas largas ojivas; esos techos, esos gigantes que alzan sus manos hacia el cielo, esas dos catedrales, la una anciana y de rodillas, arrugada, inválida, agazapada contra el suelo y al arrimo de su hija, la otra flamante y en pie, hermosa, inmensa, lozana, respirando vida en su robusta mole? ¿Para vos no dicen nada esos cien colegios y conventos, obra de la ciencia y la piedra reunidas? ¿Y esos palacios de los grandes señores, esas paredes llenas de escudos y rejas, indicio de soberbia y precaución? ¡Dichosa edad aquella en que el alma ha 
encontrado siempre de qué alimentar su insaciable hambre! Para las almas religiosas el monasterio, para las heroicas la guerra, para las apasionadas el amor, más hermoso cuanto más contrariado, para todas la galantería, los grandes afectos, los sacrificios sublimes, las muertes gloriosas... La sociedad vive impulsada por una sola fuerza, la pasión... (Galdós 2007: 340-341).

Todo el capítulo XX con el deambular nocturno de Araceli y miss Fly por la ciudad buscando la calle del Cáliz para rescatar a Inés se convierte en una extraordinaria crónica-reportaje de Salamanca, sus monumentos, la Universidad, las catedrales, el laberinto de viejas callejas, la muralla, el río, en definitiva, Galdós hace ahí alarde de sus extraordinarias dotes descriptivas de ambientes, que con el tiempo harían de él un verdadero cronista urbano, sobre todo, a partir de 1881 con la serie de novelas contemporáneas que inicia $L a$ desheredada.

En resumen, la función de las aventuras de miss Fly en la folletinesca trama argumental de La batalla de los Arapiles es servir de contrapunto a la aventura bélica principal, la toma de los Arapiles por el ejército español-inglés-portugués. $Y$ en cierta medida también acaba por ser una historia intercalada al modo de las historias interpoladas en El Quijote.

\section{Conclusiones}

En los Episodios Nacionales están ya en germen muchas de las estrategias narrativas del Galdós novelista posterior y muchos de sus logros que hacen de él un autor imprescindible en el canon de la literatura española y europea de su tiempo.

Galdós es un novelista de raza, con una temprana y fecunda intuición del hecho narrativo, con un dominio extraordinario del lenguaje, con una gran capacidad de observación y con una extraordinaria memoria, pero no improvisa, pues creo que se puede afirmar, desde episodios como el que acabamos de analizar, que tenía clara conciencia de su quehacer literario. Hay que descartar definitivamente la idea de un escritor ingenuo, a favor de un autor riguroso, de amplia cultura literaria, lector voraz de folletines, de Cervantes, de novela picaresca, de obras dramáticas como El don Juan de Zorrilla, de los costumbristas españoles y de los mejores novelistas europeos de su tiempo, Balzac, Dickens, Zola, Tolstoi... Por tanto plenamente consciente de su tarea como escritor, en la que los Episodios serán un magnífico y temprano banco de pruebas.

Galdós comparte con Giner de los Ríos su filosofía de la historia y el interés por Herder, es decir el estudio de las auténticas raíces de un pueblo a través de la literatura y el arte. Ambos participan del respeto a la tradición pero sin convertirse en panegiristas del pasado remoto, arqueológico, es decir muerto, sino con una voz que habla a la nación de la realidad actual en circunstancias históricas concretas (Rodgers 1988: 44).

Esta idea de llevar a la novela la historia actual está presente desde el texto canónico de las «Observaciones sobre la novela española contemporánea» de 
1870, verdadero manifiesto del realismo español hasta el discurso de ingreso en la Academia «La sociedad presente como materia novelable» (1897). En esencia no cambia nada en sus principios estéticos fundamentales, pero sin renunciar a la esencia evoluciona constantemente al compás de los tiempos: novela histórica, novela de tesis, novela contemporánea (realista-naturalista), novela espiritualista, psicológica, dialogada, dramatizada, siempre con la historia no sólo como telón de fondo sino como principio motor de la actuación de los personajes.

Galdós se presenta en los Episodios como un escritor comprometido con su pueblo en el sentido que lo habían preconizado Herder y Giner y que él mismo había defendido en las mencionadas «Observaciones», es decir el escritor no puede proponer soluciones pero sí puede y debe revelar verdades:

No es el novelista el que ha de decidir directamente estas graves cuestiones -escribe-, pero sí tiene la misión de reflejar esta turbación honda, esta lucha incesante de principios y hechos que constituyen el maravilloso drama de la vida actual (Galdós 1999: 107).

Esta tarea de reflejar la historia actual la va a emprender Galdós desde ese mismo momento, 1870, consciente de la importancia de las fuentes del pasado clásico tanto en pintura como en literatura: Velázquez y Cervantes serán sus modelos, pero también consciente de que es necesaria una inminente renovación de la novela espańola atendiendo a los paradigmas de la mejor novela europea de su tiempo. El primer paso será la primera serie de los Episodios Nacionales, que no responden a la novela histórica convencional sobre el pasado remoto practicada hasta entonces en España por López Soler, Fernández y González o el mismo Larra, sino que Galdós se propone una serie de novelas sobre el pasado histórico inmediato, que puedan poner al descubierto las raíces de los conflictos actuales. De ahí su propuesta de novela española, realista y contemporánea.

Y hasta cierto punto la idea de la intrahistoria unamuniana está en buena medida en germen en los Episodios Nacionales de Galdós «donde el fluir de la historia es representado a través de los acontecimientos en la vida diaria de las personas humildes, es un resultado, consciente o no, del popularismo y del particularismo de Herder» (Rodgers 1988: 45).

Galdós en el prologuillo a La sombra, publicada en La Revista de España en 1871, y editada por Hernando en 1909, defendía su inclinación hacia la literatura realista y pedía al público que fuese indulgente con sus escarceos de literatura fantástica con estas lúcidas palabras:

Se empeña uno a veces, por cansancio o por capricho, en apartar los ojos de las cosas visibles y reales, y no hay manera de remontar el vuelo por grande que sea el esfuerzo de nuestras menguadas alas. El pícaro natural tira y sujeta desde abajo... y cuando uno cree que se ha empinado bastante y puede mirar de cerca las estrellas, éstas, siempre distantes, siempre inaccesibles, le gritan desde arriba: Zapatero, a tus zapatos (Galdós 1909: 3-4) 
El que así reflexiona es el novelista que dará vida a multitud de personajes durante más de treinta años, y con él no valen las simplificaciones más o menos reduccionistas, pues vivía como Cervantes con un alma dual: idealismo, ensoñación y romanticismo en la entraña de una novela histórica y realista.

\section{Bibliografía}

Altamira Rafael (1907), Cosas del día (Crónicas de Literatura y Arte), Valencia, F. Sempere y Compañía eds.

Balzac Honoré de (1842), Avant-Propos à La Comédie Humaine.

Benítez Rubén (1990), Cervantes en Galdós, Murcia, Universidad de Murcia.

Bly Peter ed. (1988), Galdós y la historia, Otawa Hispanic Studies 1, Devehouse Editions, Canadá.

Cardona Rodolfo (2004), Del heroísmo a la caquexia. Los "Episodios Nacionales» de Galdós, Madrid, Ediciones del Orto-Universidad de Minnesota.

- (1968), «Apostillas a los Episodios nacionales de Benito Pérez Galdós de Hans Hinterhäuser», Anales galdosianos, III; pp. 120-121.

Fernández Montesinos, José (1959), Costumbrismo y novela, Madrid, Castalia.

- (1967), Galdós I. Madrid, Castalia.

Fernández Prieto Celia (1998), La novela histórica: poética de la novela histórica, Pamplona, Eunsa.

Ferrer Benimeli José A. (1979), «La masonería en la Primera Serie de los Episodios Nacionales», Actas del segundo Congreso Internacional de Estudios Galdosianos, vol. I, ed. del Excmo. Cabildo Insular de Gran Canaria, 1979; pp. 60-118.

Gómez Baquero, Eduardo, Andrenio, (1918), Novelas y novelistas, Madrid, Calleja.

González Santana Rosa Delia (2008), «Miss Fly o El hada redimida», Universidad de las Palmas de Gran Canaria, Biblioteca Universitaria, pp. 152-180.

Gullón Ricardo (1970), «La historia como materia novelable», Anales galdosianos, 5 (1970), 23-37.

- (1972), «Los Episodios: la primera serie», Philological Quarterly, 51, 292-312.

- (1974), Episodios nacionales: problemas de estructura. El folletín como pauta estructural, Letras de Deusto, núm. 8 (número extraordinario dedicado a Galdós), 33-59.

- (1960), Galdós, novelista moderno. Madrid, Taurus.

Hinterhauser Hans (1963), Los Episodios Nacionales de B. P. Galdós, Madrid, Gredos. Lida Clara E. (1968), «Los Episodios nacionales. Una historia del liberalismo español», Anales galdosianos, III, pp. 61-77.

López Morillas Juan (1965), «Historia y novela en el Galdós primerizo. En torno a La fontana de oro", Revista Hispánica Moderna, XXI; pp. 273-285.

Menéndez Pelayo Marcelino (1964), «Discurso de acogida a Pérez Galdós en la RAE», 1897, en Discursos, ed. de J. M. Cossío, Espasa-Calpe, Clásicos Castellanos.

Montero Paulson Daría J. (1989), «La mujer "quijote" y la rebelde en la obra de Benito Pérez Galdós"; Actas del Tercer Congreso Internacional de Estudios Galdosianos, vol. I ed. del Excmo. Cabildo Insular de Gran Canaria; pp. 273-302 
Ortega Soledad (ed.) (1964), Cartas a Galdós, Madrid, Revista de Occidente.

Penas Varela, Ermitas (2014), «La estética teatral en la segunda serie de los Episodios nacionales», Estéticas y estilos en la literatura española del siglo XIX, M. Sotelo, E. Rubio, V. Trueba, M. Cristina, B. Ripoll y J. Cáliz, eds. Barcelona, Publicacions i Edicions de la Universitat de Barcelona.

Pérez Galdós Benito (1999), "Observaciones sobre la novela española contemporánea» en Ensayos de Galdós (Laureano Bonet, ed.), Barcelona, Península.

- (2007), La batalla de los Arapiles. Episodios Nacionales III, (Emilio Blanco, ed.), Madrid, Biblioteca Castro.

Regalado García Antonio (1960), Benito Pérez Galdós y la novela histórica española 1868-1921, Madrid, Ínsula.

Rodgers Edmonn (1988), «Teoría literaria y filosofía de la historia en el primer Galdós», en Peter Bly ed. Galdós y la historia, Otawa Hispanic Studies 1, Devehouse Editions, Canadá, pp. 35-45.

Rubio Cremades Enrique (1982), "Novela histórica y folletín», Anales de Literatura Española, 1, Universidad de Alicante; pp. 269-281.

Seco Serrano Carlos (1970), «Los Episodios Nacionales como fuente histórica», Cuadernos Hispano-Americanos, 250-252; pp. 256-284.

Smith Alan (1982), El epílogo a la primera edición de La batalla de los Arapiles, Anales Galdosianos XVII, pp. 105-108.

Triviños Gilberto (1987), Galdós en la jaula de la epopeya. Héroes y monstruos en la primera serie, Barcelona, Ediciones del Mall.

Troncoso Dolores (2006), «Introducción» a Pérez Galdós, Episodios Nacionales. Primera serie, Barcelona, Destino, Ancora y Delfín, pp. 7-22. 
